Article

\title{
Choosing to Stay: Alternate Migration Decisions of Ghanaian Youth
}

\author{
Mary Setrana \\ Centre for Migration Studies, University of Ghana, Accra, Ghana; E-Mail: mbsetrana@ug.edu.gh
}

Submitted: 28 September 2020 | Accepted: 15 December 2020 | Published: 25 March 2021

\begin{abstract}
This article focuses on nationals from Ghana who have lost interest in pursuing migration dreams to Europe and North America after failed attempts to migrate. Many less experienced youths who attempt to migrate to Europe and North America face challenges such as strict immigration laws, high cost of financing migration plans, or illegal recruiters. Some risk their lives through dangerous routes to achieve their migration goals. The negative consequences recorded are numerous, including death en route to Europe and North America. Using life stories, this article lets failed migrants recount the frustration, wasted resources and years spent to fulfil their migration dreams. It discusses individual factors such as experiences that affect the decision not to pursue migration dreams despite the culture of migration in their communities. The article concludes that strict immigration policies in Europe and North America have restricted international migration among less experienced and less skilled youth in Ghana, leading to personal decisions not to migrate but adjust to the conditions at home, and later describing their stay as a preferred decision.
\end{abstract}

\section{Keywords}

involuntary mobility; voluntary mobility; stayers; Ghana; migration aspirations

\section{Issue}

This article is part of the issue "Decision-Making under Uncertainty: African Migrants in the Spotlight" edited by Didier Ruedin (University of the Witwatersrand, South Africa / University of Neuchâtel, Switzerland).

(C) 2021 by the author; licensee Cogitatio (Lisbon, Portugal). This article is licensed under a Creative Commons Attribution 4.0 International License (CC BY).

\section{Introduction}

Why people stay has received less attention in the migration discourse, despite the relatively high proportion of immobility compared to the smaller percentage (3.5\% as a proportion of the world's population) of persons who are internationally mobile (UNDESA, 2020). The situation is much more worrying, even though increasingly, globalisation has led to advancement in technology and telecommunication while at the same time, facilitating movement and interactions through transnationalism (Carling, 2014). The works of scholars like Massey et al. (1999) and De Haas (2014) on immobility have shown that explaining only why people move offers a unidirectional understanding of the migration narrative. The frequent neglect of immobility and overemphasis on migration has prompted Carling (2002) to describe the contemporary situation as an age of immobility. Schewel (2019) calls this neglect of immobility a "mobility bias." In Sub-Saharan Africa, where human mobility is enduring (Tonah, Setrana, \& Arthur, 2017), studies by Esipova,
Ray, and Pugliese (2011) have shown that over half of adults (51\%) in Sub-Saharan Africa do not desire to move to another country.

Migration theories mainly explain why people migrate but not why they stay. For example, the neoclassical economics theory expounds international migration in terms of differences in wages, which causes migrants from low-income countries to move to highincome countries (De Haas, 2010). Meanwhile, these disparities have not translated into increased volumes of people moving from less to higher endowed countries, leaving the majority of the world's population immobile (Carling, 2002). The new economics of labour migration theory explains why households determine who and why some individuals in the household deserve to migrate rather than others. This is because migration is seen as a means by which the households diversify resources as a strategy to decrease their income risks (De Haas, 2010). Here too, there is reason to believe that not all those who have been chosen by households are able to realise their migration goals, thereby contributing to the 
high immobility numbers. The focus of these theories on reasons why people migrate leaves a gap in the migration literature about why people stay (e.g., Massey et al., 1999). This research gap calls for the need to explore factors and processes of choosing to stay as alternate migration decision.

This article seeks to fill this knowledge gap by exploring the challenges of migrants leading to the staying processes as well as reasons influencing their decision to stay. The article focuses on Ghanaian youth who have lost interest in pursuing migration dreams to Europe and North America after failed attempts. Using life stories, the article recounts potential migrants' frustrations, wasted resources and years spent in their attempt to fulfil their migration dreams of travelling to Europe and North America. The article relies very much on Carling's aspiration/ability model. Additionally, the article contributes substantially both to the model and to the immobility discourse through in-depth exploration of the processes through which potential migrants move into immobility: particularly from involuntary immobility to voluntary immobility; and why? This contribution is important for us to understand what happens to unfulfilled migration aspirations and whether to pursue migration projects despite the obstacles or non-migration.

\section{Conceptualising Immobility: A Review of Literature}

The aspiration/ability model remains a coherent framework for analysing immobility with a central focus on involuntary immobility in the migration process. In Carling's aspiration/ability model, "a migration 'aspiration' is defined simply as a conviction that migration is preferable to non-migration" (Carling, 2002, pp. 12-13, also cited in Carling \& Schewel, 2018, p. 946). By aspirations, Carling meant "a specific type of attitudes: a subjective evaluation of an object or concept which in this case," and he refers to it as migration (Carling, 2014 , p. 3). Migration aspirations are described as "the social norms, and expectation about migrating or staying, opportunities for migration and the structural forces facilitating or constraining particular migration trajectories" (Carling \& Schewel, 2018, p. 952). In the model, the varying degrees of migration aspirations shows that for those who aspire to migrate, some will have the ability to do so; they are the 'actual migrants' while others may have the migration aspiration but may lack the ability to do so; and they are described as 'involuntary non-migrants' (Carling \& Schewel, 2018). Carling further distinguishes between involuntary and voluntary migrants based on their abilities. The voluntary non-migrants are "those who stay because of a belief that non-migration is preferable to migration" (Carling \& Schewel, 2018, p. 946). Taking inspiration from Sen's (1997) capabilities approach and De Haas' (2014) aspiration-capability framework, Carling and Schewel (2018, p. 956)) define ability as "the element that symbolises whether potential migrants can turn their migra- tion aspirations into actual migration." These abilities are equally important for potential migrants who eventually make the alternate choice of staying, instead of turning migration aspirations into reality.

As a point of departure, this article operationalises ability, rather, as the element that represents whether potential migrants would turn and channel their migration aspirations into a non-migration decision. Here, ability is an opportunity for the involuntary immobile person to exercise his or her agency to move into the category of voluntary immobility. Agency is used here to refer to the individuals' ability to exercise their own free will and make their own choices (Emirbayer \& Mische, 1998), in this case, making a choice to stay voluntarily. The process of staying in itself can be conceptualised as an element of agency (De Haas, 2014). The involuntary immobile makes conscious effort to invest in $\mathrm{him} /$ herself in the home country to enable growth and empower him/herself to pursue many different life paths. The extent to which agency is implemented depends on several other factors-individual, social and economic, among others. Emphasising this point, Schewel (2019, p. 330) argues that "for many non-migrants, staying reflects and requires agency; it is a conscious choice that is renegotiated and repeated throughout the life course."

Still in the aspiration/ability model, some major micro- and macro-level elements that are analysed include the emigration environment and the immigration interface (Carling, 2002, p. 13). The emigration environment seeks to question why several people want to emigrate. Immigration interface includes all the available modes of migration, with associated requirements, costs and risks (Carling, 2002). Migration aspirations and the ability to migrate are informed by both the macro- and individual-level factors. The macro-level factors include "social, economic and political context, available modes of migration, with associated requirements, costs and risks" (due to restrictive immigration policies; Carling, 2002, p. 13). The micro-level factors are "gender, age, family migration history and social status, educational attainment and personality traits" (Carling, 2002, p. 13). The model helps in framing the analysis and unearthing individual's aspirations and agency to choose to stay or not to stay. It further explains why and how Ghanaian youth who aspire to migrate to Europe and North America, eventually decide to stay.

In spite of the usefulness of this model, what is not clear is the aftermath of people within the involuntary immobility, whether they remain involuntary immobile for the rest of their lives or decide to move from being involuntary immobile to voluntary immobile: At what point do they engage in such decisions? What processes shape such decisions and why? The migration aspiration of the Ghanaian youth is not a guarantee that migration is automatic or even attempted. Among these youth, the processes of pre-migration may be frustrating and expensive; and may decide to find alternative means of meeting their life aspirations. Indeed, as expounded by Carling 
and Schewel (2018, p. 2), not everyone-in this case, not every Ghanaian youth-aspire to migrate, even if they have all the resources at their disposal (be they financial, social and capital resources) to do so. Despite the culture of migration in some contexts (Schewel, 2019, p. 3), some may not harbour migration aspirations for various reasons.

Relatedly, Schewel (2015, p. 8) highlights the notion of retain, repel and internal constraints as factors likely to influence immobility decisions. She further categorises these factors into economic and non-economic factors. Retain factors are the "favourable conditions that encourage staying at home" (Schewel, 2015, p. 8). The economic retaining factors include rational choice theory, and location-specific advantages accumulated overtime. Rational choice theory stipulates that people will prefer staying if the cost of migrating offsets the benefits of staying. Meanwhile, the location-specific advantages highlight that when people have 'insider advantage' due to consistent location and relationship with a place, the likelihood of them staying is high (DaVanzo, 1981). Among the retaining non-economic factors include voice, loyalty, religion, family and community ties (DaVanzo, 1981).

Repel factors describe "conditions elsewhere that diminish the aspiration to migrate" (Schewel, 2015, p. 8). Repelling economic factors comprise job opportunities in potential destination and financial costs of migration (cf. Epstein, 2008). Repelling non-economic factors also consist of stress of leaving home, dangers of the journey, xenophobia and racism. Knowledge of these factors are usually disseminated through people's own personal experiences as a result of failed migration through networks, media reportage and migration messages (Schewel, 2015, p. 8).

Internal constraints factors are "more nuanced influences on decision-making at the level of individual psychology that attempt to explain why some people may not meaningfully consider alternatives to staying" (Schewel, 2015, p. 8). Internal constraints on decision making cuts across threshold of indifference, lacking achievement motivation, an underdeveloped capacity to aspire, and risk aversion

These factors serve as a starting point to understand the elements that influence the decision to stay. As noted by Schewel (2015), these factors are not necessarily mutually exclusive in a real-world situation. Debates that promote economic reasons as dominant factors are flawed mostly in their argument: Complex reasons have led to why people take certain decisions, even if they are economic reasons, although often there are other social reasons. Fischer and Malmberg (2001), in their study in Sweden using life course perspective, noted that people who have strong ties to, for example, places and people may not be motivated to move. Particularly, they cite children, owning a house, marriage and employment as social circumstances that can cause people to stay and not move. They also offer explanations for the non-economic values and aspirations which could refer to people who prefer to stay and contribute to shaping the economic and political environment than to exit (Hirschman, 1970; Schewel, 2015).

\section{Study Context, Research Methods and Profile of the Participants}

The case of Ghana is important in this study because, in 1960, Ghana recorded large numbers of immigrants from in and around Africa due to its economic and political stability; it later turned into a major migrant sending country due to poor economic and political environment. However, since the last two decades, the changes in global issues and the relative political and economic stability in the country has resulted in a balanced net migration rate (Quartey, 2009), which has led to varied mobility patterns including emigration, immigration and transit migrations at international levels (Quartey, 2009). The improved performance of the national economy since the 1990s may have had some potential influence on staying behaviours. In 2008, Ghana attained the status of a middle-income country with a per capital income of US \$1500 in 2009. In addition to income earned from the production of gold, cocoa, tourism, exports of non-traditional goods and remittances from Ghanaians abroad, Ghana started the commercial production of oil in December 2010. These developments resulted in considerable confidence in the economy by foreign and local investors. Additionally, the general economic conditions for doing business in Ghana has been quite favourable and have a high likelihood of influencing people's decision to stay in the country, especially in the midst of tightened immigration laws and restrictions on travelling abroad, particularly, to Europe and North America that require valid travel and employment documents (Setrana \& Tonah, 2016, p. 553).

Seven participants (five males, two females) were recruited for this study through chain referrals by the initial contact and personal contacts. All seven participants included in the study were potential migrants who were unsuccessful in their attempts to migrate to Europe or North America; but currently, have little to no aspiration, desire or dream to migrate to Europe or North America. These participants were purposively selected from the city of Accra-a primary destination for different migrants both local and international (cf. Setrana \& Tonah, 2016). While four of the participants had made two failed attempts, all the other three had made one attempt to migrate to Europe or North America. A key challenge for this study is related to difficulties in identifying failed female potential migrants because, in addition to not wanting to share their own experiences, Ghanaian women do not take much risk when it comes to migration to Europe or North America through dangerous irregular channels.

I used snowball technique to recruit participants for this study; the failed potential migrants are hard to reach because the topic of failed migration is sensitive and 
difficult to talk about. I used flexible in-depth interview guides to conduct all the interviews. The interviews were organised using a life history approach. A key reason for using this technique is that it allowed gaining indepth understanding (cf. Eastmond, 2007) of the issues but with emphasis on participants' migration aspirations, and experiences as well as their staying processes. The technique also enabled me to gain individual subjective evaluation of their social experiences including their own failed migration aspirations, migratory processes, the material and non-material dimensions of immobility and the decision to pursue (im)mobility. This allowed for unearthing commonalities or variations within and across the participants own unique social experiences.

Thematic analysis was done on participants' migration decisions and attempts, decision to stay as well as the factors that influenced their decision to stay. Although, discussing immobility experiences with the failed potential migrants does not necessarily place them in a vulnerable position, I was aware that conversations related to past struggles linked to any attempt to migrate to Europe or North America could engender uneasiness. Consequently, established guidelines for dealing with various ethical issues, including informed consent and guarantees of anonymity and confidentiality, were strictly observed to protect these participants. Moreover, the interviews were conducted in locations that allowed the participants to speak freely and safely. Each participant decided on and chose a preferred location for the interview. Several contacts were made with participants to build trust prior to the actual interview date. I introduced the purpose of the research and secured informed consent from each participant before the actual interview. The interviews were conducted in English and Twi. The ones conducted in Twi were translated into English for analysis. I use pseudonyms in the narration of the participants' experiences to protect their identity. The in-depth nature of the interviews contributes to adding to the abstract theories of the migration and immobility discourses, in particular the aspiration/ability model by Carling (2002). However, in replicating such a study, the contextual specific factors such as migration history and culture, economic and social milieu are crucial and must be taken into consideration.

The participants were between the ages of 19 and 28 at the first time they took the decision to pursue their migration goals. The Table 1 shows the detailed demographic characteristics of the participants.

\section{Findings and Discussions}

\subsection{Migration Processes and Decisions}

The preferred destination among the participants were UK, Germany, Italy, Spain, US and Canada. Depending on the preferred destination, some countries in Europe were described as transit countries by the participants, in their words, a "stepping stone" to the actual preferred destination. In their previous attempts, transit countries included Equatorial Guinea, Nigeria, South Africa, Benin and Saudi Arabia. Five of the participants contacted agents or connection persons, one was supported by his association and another was seeking the opportunity through the assistance of his friend and an agent.

The in-depth interviews make it clear that the decision to migrate is never a one-time event (see also Setrana, 2017), rather it is a process spanning many years. Indeed, the decision to migrate is a stepwise process that includes earning money for the journey, finding the right contacts and obtaining migration information. During the early youthful stages in the lives of these participants, migration was perceived, in their words, as the "only means to an end." The path to a successful life could only be imagined through the lens of migration. While the purpose of migration differs for many young people; for these participants, the main motive for migration was economic, such as better employment and income, among others. However, others stated that they were influenced by their peers.

Although economic factors were the main reasons for migration, other social factors were also discussed. At the age of sixteen, Kidi migrated from his village in the Northern zone of Ghana to a suburb in Accra to pursue his migration to Europe dream. On his arrival, he contacted and settled with his eldest sister. Accra was a transit location for him to earn income for his journey as well as find agents who could assist him move to Agadez in Libya. Between 1997 and 2008, Kidi worked tirelessly and saved enough money to self-finance his trip. His decision to migrate was in part influenced by the display of wealth by returnees from Nigeria. He stated: "I made up my mind to migrate when I saw people who returned from

Table 1. Demographic characteristics of the participants.

\begin{tabular}{llllcr}
\hline Name & Sex & Current Education Status & Job & $\begin{array}{c}\text { Age when first pursuing } \\
\text { migration goal }\end{array}$ & Current Age \\
\hline Faud & Male & Junior secondary certificate & Trader & 24 & 38 \\
Kidi & Male & Junior certificate & Trader & 23 & 43 \\
Dul & Male & Senior certificate & Trader & 24 & 32 \\
Ako & Female & Primary certificate & Caterer & 27 & 45 \\
Dina & Female & Senior secondary certificate & Business woman & 25 & 38 \\
Mansh & Male & Senior secondary certificate & Business man & 28 & 43 \\
Zuri & Male & No formal Education & Trader & 19 & 22 \\
\hline
\end{tabular}


Nigeria display lots of wealth." In the 1980s, Ghanaians who emigrated to Nigeria came back home with lots of goodies. However, after Nigeria's economic crises, Ghanaians began to move to Libya to work as both professionals and labourers. Kidi further explained:

For those young guys from my village who migrated to Libya, they moved on to Italy while others who moved to Morocco continued to Spain. Migration to Europe through Libya became a necessary competition in my village since almost every household had a migrant living in these places. I didn't have any family member abroad and so, I decided to initiate this process myself on behalf of my family. But I had no money at that time. One of my friends from my village who had successfully landed in Italy, contacted me after his arrival to give me information on his experience through the desert to Libya. He knew I was also planning to migrate to Europe; he gave me the contact details of the agent who assisted him to also aid me in my process. He asked me to find a minimum amount of $\$ 400$ which is the boat fee from Agadez to Italy.

Kidi's narration shows how his choice of migration channel was influenced by the kind of information he received from his contact person. Kidi decided to migrate using an irregular route because this was the channel used by his network. His choice of channel was not only associated with strict immigration policies, but also lack of information among potential migrants, especially those who had less education and experience.

In the early years of his youthful life, Faud made the decision to migrate to Europe or North America. He lived and grew up in a suburb of Accra, a community, where migration is seen as the norm for every young person. He said:

I had a bit of money, and my brother also supported me financially, because he was aware of my decision to migrate. After my high school education in 2006, I worked hard to mobilise money for migration. In the evenings, all the borgas [term used to refer to the return migrants or those in diaspora] gathered at the 'base' [a local English expression which means a physical place of meeting for a group of people]. Here, they discussed all kinds of issues, including migration opportunities and challenges, some were from Italy, the USA, etc. They always had lots of foreign currencies with them and this further heightened my desire to migrate. Because of them, I just convinced myself that Europe must be a nice place for me to live.

Similar to Kidi's experience, Faud's influence was due to peer and community pressure. However, the mode through which he gained migration information was quite different from Kidi's: He gathered information on migration through his interactions with return migrants.
On the other hand, the two females rather sought a migration opportunity through other means such as labour export, marriage and/or visit. Ako shared her story:

I had the dream to migrate to Europe as I was growing up, but I had no relation or friend there. I was told by my colleague that I could apply to work in Saudi Arabia. And hopefully from there, find my way to Europe. I accepted to work in Saudi Arabia as a domestic worker. My plan was to continue from Saudi Arabia to Germany or somewhere Europe. I got the job in Saudi; my employers paid all the fare and lo and behold I was in Saudi.

Dina also said:

After my high school education, my father hired a connection man to assist me migrate to the UK or anywhere in Europe or North America. The whole process was sponsored by my dad. Because I knew I will be migrating abroad, I didn't pursue any further education, but was waiting for the chance to fulfil my migration dream. My father thought that the best security he could give me was to send me out of the country.

Similar to the two male stories, the narration of the females points to ways of raising money and gathering resources to fund the desire to migrate. There is a difference in the ways and sources of fundraising among the participants: Kidi and Faud sought to work hard in the urban area to mobilise funds for their journey, although Faud was supported by his brother. Ako found a job in Saudi Arabia that then allowed her to gather enough resources to pursue her dream of migrating to Europe or North America. On the other hand, Dina's father was wealthy and found migration abroad as the most secured future he could offer her daughter, so, she could also support her other siblings once she managed to migrate.

As part of the migration preparations, migrants either made the decision alone or with their families. For the two females, both of their migration decisions were taken with their families. In both cases, Dina and Ako were the first daughters of their families. In Ako's view, the only means to help her family stay out of poverty was for her to migrate. The decision to migrate was influenced by the migration culture in the communities of the participants, access to information, networks as well as interactions with return migrants.

\subsection{Migration Connections and Frustrations in the Process}

The frustrations narrated by the migrants were itemised under the various attempts they had each embarked on, namely the resources (i.e., time, personal energy and money) they had wasted in these processes and the prob- 
lems of navigating strict immigration policies. The narration of the participants shows that attempts to reach Europe or North America comprised of many efforts and frustrations, such that they claimed to have engaged in numerous sacrifices that were likely to influence any subsequent migration decisions. Beyond the problems associated with immigration policies (Carling, 2002; Spijkerboer, 2018), other forms of frustrations such as time wasting and personal energy drain, are hardly accounted for in the discourses surrounding migration processes. They may broadly be referenced within costs and risks, but in such context, time may lose its significance because calculating time spent may be a difficult task compared to monies spent.

In this section, I discuss the detailed account of the failed attempts by some of the participants. At the age of twenty-one, after his senior high school, Dul attempted to migrate to the USA through Canada and Mexico on two occasions. He recounts his two-times failed attempts as follows:

In 2012, my relative who lived in America connected me to his friend in Canada. The 'deal' for the visa was in South Africa. The agent processing the documents directed me to submit my passports to the Canada High Commission in South Africa for processing. I didn't know that I was expected to have a visa for South Africa to demonstrate that I was indeed in the visa issuing country. The journey to South Africa was through illegal means, I couldn't have any visa as evidence. It took me more than one month before retrieving my passport with the Canadian visa from South Africa, I was issued a three-months tourist visa. The challenge afterwards, was how to get on board with my passport without any South African stamp but with a Canadian visa from South Africa. On three occasions, I couldn't board the plane because I had a strict flight attendant. I didn't want to be questioned as to why I had a Canadian visa from South Africa; I was scared. On all the three occasions, I did change my flight and paid the penalty fee of $\$ 100$. The process repeated itself until the visa expired.

The next connection after the Canada episode was to have a Mexican visa, which could then help me enter America through Mexico. There was no Mexican Embassy in Accra at that time. To have a Mexican visa, the consular had to give approval from Ghana for me to go to Abuja, Nigeria, where I could submit my visa application documents. But the good news was that I did skip the Accra approval and travelled directly to Abuja. I made a commitment fee of over $\$ 400$. I travelled to Abuja with seven other guys for this 'connection' [a local English expression which means either contract or project, also sometimes referred to as a 'deal' by the participants]. The Ghana agent handed us over to his partner in Abuja. Fortunately, the process in Abuja was smooth, we eventually had our visas with the help of the second agent. Now, there comes the problem! In addition to the $\$ 400$ commitment fee, we also paid $\$ 500$ as visa fees, making a total of $\$ 900$. The deal as we got to know was that each person was supposed to pay $\$ 1,500$ for the visa which the agents didn't inform us. We were hoping our agent in Ghana will transfer the $\$ 400$ each we paid to the Nigerian agent, but he refused. After four weeks of being stranded in Nigeria, we returned to Ghana but without our passports. I further mobilised the remaining $\$ 1000$ to be paid to the Nigerian agent through my Ghana agent, but the agent squandered the money. Up until now, I never received my passport from Nigeria.

Very important to involuntary immobility category, using Dul's experience, are the connectedness of intermediaries across countries which is gaining prominence in the migration industry debates. The challenges of immigration policies go beyond obtaining visas, but other obstacles need to be overcome as part of the immigration interface which was a problem for Dul and his friends. As hinted earlier, an average cost of \$US 3000 was spent during this unfruitful process, not only has money been lost, but part of his prime years of economic activeness was also spent on chasing a migration project. This was the turning and final point for Dul; he said that he felt such monies could be invested in better opportunities back home. Expanding on the aspiration/ability model by Carling, involuntary immobility among these youth has not been a permanent stage for them. Rather, the immigration interface challenges compelled them to find alternate decisions to their migration project, progressing to a state of voluntary immobility. In this case, voluntary immobility could be described as a state of exercising agency on the part of the frustrated participant, to divert human and financial resources, which would have been spent on the unsure migration project towards their own personal well-being and growth in Ghana.

Faud decided to fulfil his migration goal at a time when he was single with no child. He joined the Ghana Supporters' Union for several reasons, including the opportunity to migrate and visit other countries. The Ghana Supporters' Union is an association with the aim of cheering up the national men and women football teams to ensure victory for Ghana in and outside the country. Through this association, Faud said he got the chance to live in Equatorial Guinea with the aim of continuing to Europe. He narrated his attempt this way:

Through the supporter's union, I had the chance to migrate to Equatorial Guinea. I went to Equatorial Guinea by air. I was issued my visa from Togo. Life in Equatorial Guinea was very difficult. The Black Stars [Ghana national football team] were having a tournament, so, I went with them on a tourist visa. At the end, it was waste of money. I didn't get the chance to work, neither did I have the opportunity 
to move to Europe. I was informed that once I managed to arrive in Equatorial Guinea, obtaining any European visa could be easy compared to Ghana. When I extended my stay after the tournament, the police chased me out of the country. About 400 of us were arrested by the Police in Equatorial Guinea and later deported.

Upon this experience, Faud decided to stay in Ghana because it is his home. Since he had sold his business and invested the money in the Equatorial Guinea trip, he had to find capital to start a new business. According to Faud, he did not have the financial resources to pursue his migration project. Relating this finding to the aspiration/ability model, Faud lacked the ability (e.g., restrictive immigration policy, illegal entry) to achieve his migration project; and therefore, decided to stay in Ghana. He willingly took a decision to begin his economic life again (exercising his agency), but strategically veer his human and financial capital (the left-over available ability) into sustaining himself in Ghana without investing anymore in migration aspirations.

Kidi said he finally mobilised some money in the urban centre at the age of sixteen with only basic secondary school education. He had a cash fund of $\$ 500$ that could support his trip to Libya and a driver's license. He said:

I left Accra one morning to visit my brother in Cotonou; I heard it was easy to travel to Libya through Cotonou. I spent a couple of days with him and before I realised the money was 'gone.' He assured me he will help me get my money back. But things became difficult for us, so I returned to Accra to start life all over again.

Kidi's narration shows that when he lived in Cotonou, he did not have visa issues because Benin and Ghana are both members of the ECOWAS, enjoying free movement. However, he said, his main challenge was his trusted brother who squandered his money. The interviews depict how he had to find a job and earn some money before he could pay for his transportation back to Ghana. From the in-depth interviews, participants emphasised the important role trust plays in the migration processes, and the fact that having money and smooth immigration policies were not enough because they sometimes made them vulnerable to exploitation. An example is portrayed in Kidi's narration. Mistrust has emerged as a key factor resulting in the unsuccessful migration projects, although, (mis)trust does not arise as obvious analytical approach in discussing involuntary immobility; Lyon (2000, pp. 664-665) argues that trust operates when there is confidence in other agents, despite the uncertainties, risks and the possibility for them to act opportunistically. However, for these participants, none of their agents or intermediaries was able to achieve any of their migration projects, despite the participants' trust in them. Based on these and other related issues, Kidi also decided to forego his migration goal; and, rather, establish himself in the Ghanaian labour market.

\subsection{Choosing to Stay Is about Choosing Not To "Begin the Whole Process Again"}

The narration of the participants emphasised the fact that choosing to stay was about choosing not to "begin the whole process again." Here, the whole process as used by the participants referred to the migration process as they have narrated above. In the view of participants, they began to appreciate the need to find alternatives to their migration decisions. To the extent that, even when opportunities of migration are presented on a 'silver platter,' their progression from involuntary to voluntary immobility does not compel them to revert their current decisions. Just as migration drivers influencing migration can be strong determinants, the alterative-choosing to stay-could even be stronger. Supporting the literature discourse on immobility, choosing to remain reflects and requires agency that needs to be negotiated over time (Schewel, 2019) in the context where migration is a culture and the goal of many other youth. Dul says, he has given up after several failed attempts. He narrates how he arrived at his decision to remain. He said:

After all those frustrations since 2013, I have given up on my migration decisions. I felt I have wasted so much time and resources, all in the attempt to go to North America. Shockingly, in recent times when I need those offers no more, I have been receiving invitations to migrate for all kinds of reasons including work. But I have given up. Recently, a friend of mine abroad said his company in UK needed to recruit workers, he asked if I was interested but I refused. He sent me invitation letter, but I explained to him that I had businesses to take care of which needed my attention. He later asked if I could recommend someone; my cousin is now working in the UK. The invitation was genuine, he paid for nothing, and no bank statement, among others. Within some few days, the visa was ready. No struggle!

According to Dul's narration, unlike his previous experience, he has an invitation letter and a job offerthe two elements he struggled to acquire in his earlier failed migration attempts. These elements represent the key immigration factors for Dul to bounce back to his migration aspirations, however, because he is voluntarily immobile, he rejected the offer.

The participants indicated that the major reasons for remaining voluntary immobile are due to economic reasons such as having better/dignified employment, receiving stable income, better opportunities and better use of time and human resource. The participants also indicated non-economic factors such as the desire to stay 
with family or support development back home, as reasons for staying in Ghana (cf. Hirschman, 1970). Although the differences between home and abroad still exist, for these participants they emphasised their preference to remain in Ghana; hardly does the literature on migration explain the above macro-level factors (referred to as emigration environment in the aspiration/ability model) of staying behind. The urge to seek a better job elsewhere, among others, are not incentives enough to drive many of these participants out of Ghana anymore. At the beginning of their youthful lives, migration and its benefits were so critical that, the challenges they faced did not scare them. They did not bother about the risks, cost and dangers. Yet later, when they have attempted and failed, they claimed to have recognised that chance and time were not on their side, and abandoned the migration goal. Kidi shared his decision to remain:

At first, we all wanted to go abroad but now, I have lost interest in migrating to Europe or North America. I can't go and start life all over again there; and as to the type of work I will be offered, even if I manage to go now, I have no idea. I might even wash dishes at a restaurant, but I won't do that in Ghana. Perhaps if one is unemployed, that person can afford to travel abroad and make a living. But if that person has a purposeful agenda or business in Ghana; then he/she has no business leaving. Even if the income is less than $\$ 50$ or $\$ 100$, it is sustainable. There is no need to worry and struggle to move to Europe or North America. For what purpose?

Similarly, Rauf also shares his decision of staying behind:

When you travel and things don't go well, you lose interest. That is how I felt. My passport has expired but since I have lost interest I am not thinking of renewal. I won't bother myself to travel because I don't really have that time to start the processes again. I am not desperate anymore. I have heard a lot of opportunities since my return. There is Dubai, and other places, but I don't want to waste my hard earn money and come back to 'square zero.'

\subsection{Staying Home as a Preferred Choice}

As indicated in the literature, "staying behaviour" could be analysed across either involuntarily or voluntarily (Schewel, 2015, p. 330) by identifying factors influencing staying-decision making. The decision to stay is influenced by layers of factors such as economic, social and personal traits. The underlying frustrations experienced during the migration process propelled the participants who were involuntary immobile to think about staying and moving into the category of voluntary immobile. The initial migration process cannot be detached from their current voluntary immobility decisions because experience has taught them lessons. Among these partic- ipants, the decision to remain voluntary immobile were influenced mainly by transnational links, positive emigration environment and individual factors such as jobs, international links with diaspora, a relatively comfortable life, marital life, children and other dependents, their extended families as well as a distressful past they would not want to go back to. Indeed, through advanced telecommunication, the immobile persons connect with the transnational space. Depending on the type of immobility, the reasons differ; when participants were involuntary immobile, their connection with diaspora was for them to achieve their migration goal while the state of being voluntary immobile is vice versa. The contact with diaspora had impact on the kind of evaluation participants made with regards to staying decisions. Generally, the literature on immobility describe these factors as retain (attractive conditions at home) and repel (conditions abroad diminishing migration desires) factors (Schewel, 2019).

Other factors influencing the voluntary immobility decisions of the participants were individual factors such as marriage, children, age, gender and education, among others. Participants' strong attachment nurtured overtime through children, owning a house, and being married are conditions that constrain migration but attracts them to immobility. It is obvious that these elements become constraints and attractions to remain in Ghana since these factors are hardly transferable or replaceable (Fischer \& Malmberg, 2001; Schewel, 2015).

Dul shared why he has decided to remain in Ghana. He said:

I am self-employed, trading in car spare parts. If I make the mistake of leaving my job to anywhere abroad, my business will collapse. Also, I am a family man, with a wife and kid. I have several dependents I am caring for. Imagine I travel in the midst of all these responsibilities, there will be a huge problem. The other problem is also that in Ghana I have my freedom. I decide when and what time to report to work; my cousin in the USA cannot do that at his work place. On the other hand, my cousin in the USA, earns more than I do here in Ghana but does not have the freedom. I know [that], with time, I will earn much more although with a bit of struggles.

One key factor for choosing to be voluntary immobile is for him to be free and independent without instructions from anyone-a factor not well highlighted in the migration and immobility debates. Similar to Dul, Mansh also shares how he enjoys his freedom. He said: "I enjoy my independence and ability to willingly decide what and how I wish to lead my life." The term 'free' expressed here by the participants can be explained by the nature of their businesses; all the participants owned and managed their own small to medium scale enterprises, giving them control over their own lives and economic activities. 
Similarly, Akos also feels that she has control over her life in Ghana compared to living abroad. She shared:

My brother who is in Southampton, for instance, told me that his monthly salary is 1,440 pounds. He pays 270 pounds for accommodation. He sometimes spends less than 100 pounds on food. At least he is able to save about 900 pounds every month. In Ghana, if one is not a politician or doing any better job, it is difficult to save. With all my years of working, I have not been able to even save $\$ 280$ per month. One advantage is that I run my own business, employing more than five workers, so, even if I am not at work, the job still progresses. Unlike me, my brother, goes to work at $6 \mathrm{AM}$ and closes at 5:30 PM. By the time he closes from work, he is tired and has to retire to bed; and the routine continues the next day.

As in the case of Akos, although the repelling factorswages abroad-is higher compared to what she earns in Ghana, the other retaining non-economic factors are stronger causing her to abandon her migration decisions. By comparing herself with her brother, she sees herself as being in a freer environment compared to her brother.

Rauf, on the other hand has a different narration. He said:

I run my shop as you can see [pointing to the shop]. I sell telephone accessories. I have my wife and child. The second baby is on the way. In Ghana, everything is hand-to-mouth; paying for rent, water bills and feeding, among others. The money I earn is not enough for me to save. I take care of many dependents from my extended family. As for the money, it's seriously not enough for me. In Europe or North America, you don't really spend much money. When you live as a group in an apartment, you don't get to spend so much. If the rent is $\$ 500$ a month, each room member will pay some amount, and this helps saving some. The problem abroad is also that I cannot find my desired job, as I am engaged in here in Ghana. Even if it has to do with bathing a dead body, once you are outside Ghana, you have to appreciate that offer because that will be the only way to survive.

Rauf shares a similar storyline with Zuri. They are both not excited about their living conditions. Both Zuri and Rauf wished for better lives, yet the distressful experience with migration, job (trading in phones) and marital status prevent them from harbouring the desire to migrate to Europe or North America. The lack of financial resources is mixed in complex factors, influencing Rauf and Zuri's decisions to stay. Although both participants have decided to be voluntary immobile, comparing themselves with other emigrants, they are not happy with their current situation. Unlike the other participants, Rauf and Zuri indicated that for them, voluntary immobility remains the only option because of family, busi- ness, lack of financial resources and other obligations. While for others, it is an alternate choice than a compelling option.

\section{Conclusion}

The article has explored the failed attempts by potential migrants, their frustration, wasted resources and years with the intention to fulfil their migration dreams in Europe and North America. The article has highlighted the factors leading to their decision to stay in Ghana. Their decision to stay is prefaced by the frustrated migration processes, mistrust, wasted time, money and personal energy and later solidified by job opportunities, positive self-evaluation with diaspora links, the relatively comfortable life than before, marital life, age, children and other dependents. Other key findings also include issues of risk taking when participants were much younger, freer, and felt could try different opportunities no matter how risky. Although the initial migration was taken based on narratives and perceptions of there being "no future" and "no alternative," it turns out that there are alternatives for these participants. The frustrated migration processes outlined are not explicitly explained in the aspiration/ability model. Consequently, the article concludes by providing a more qualitative understanding of the actual staying processes which has received less attention in the immobility literature. That is, over time, people who remain in the home country find alternative immobility goals to migration, they move from the stage of involuntary staying to a voluntary staying - a process which is not captured in the aspiration/ability model. Unfortunately, not all of the youth expressed excitement about their economic situation in Ghana, although, they had chosen to stay, they hope their situation would improve. Here, it means that based on conditions of staying, voluntary immobility could further be categorised. For these Ghanaian youth, it is not a simple matter of categorising them into involuntary and/or voluntary. The complexities highlighted by the qualitative approach of this article has shown that further studies on the actual staying process and categories of immobility are critical and needed to shape the bias discourses of migration scholars.

Additionally, the article concludes, ability (i.e., age, time) and agency are significant determinants in the staying process. Choosing to stay is an ability that demands the exercising of agency which has to be negotiated by the Ghanaian youth over a period of time, in a context, where migration is a culture and the goal of many other youth.

\section{Acknowledgments}

The project this article is based on has been funded by the Swiss-Sub-Saharan African Migration Network (S-SAM). The author is grateful for the valuable comments from the anonymous reviewers and Didier Ruedin, 
the academic editor of this thematic issue. The author would like to thank all the participants in Accra whose openness and support have made this project possible.

\section{Conflict of Interests}

The author declares no conflict of interests.

\section{References}

Carling, J. (2002). Migration in the age of involuntary immobility: Theoretical reflections and Cape Verdean experiences. Journal of Ethnic and Migration Studies, 28(1), 5-42.

Carling, J. (2014). The role of aspirations in migration. Paper presented at the "Determinants of International Migration" Conference, International Migration Institute, University of Oxford, UK. Retrieved from https://jorgencarling.org/2014/09/23/the-roleof-aspirations-in-migration

Carling, J., \& Schewel, K. (2018). Revisiting aspiration and ability in international migration. Journal of Ethnic and Migration Studies, 44(6), 945-963.

DaVanzo, J. (1981). Microeconomic approaches to studying migration decisions. In G. de Jong \& R. Gardner (Eds.), Migration decision making: Multidisciplinary approaches to microlevel studies in developed and developing countries. Oxford: Pergamon Press.

De Haas, H. (2010). Migration and development: A theoretical perspective. International Migration Review, 44(1),227-264. http://dx.doi.org/10.1111/ j.1747-7379.2009.00804.x

De Haas, H. (2014). Migration theory: Quo vadis? (IMI Working Paper No. 100). Oxford: University of Oxford.

Eastmond, M. (2007). Stories as lived experience: Narratives in forced migration research. Journal of Refugee Studies, 20(2), 248-264.

Emirbayer, M., \& Mische, A. (1998). What is agency? American Journal of Sociology, 103(4), 962-1023.

Epstein, G. S. (2008). Herd and network effects in migration decision-making. Journal of Ethnic and Migration Studies, 34(4), 567-583.

Esipova, N., Ray, J., \& Pugliese, A. (2011). The world's potential migrants: Who they are, where they want to go, and why it matters. Washington, DC: The Gallup Organization. Retrieved from http://www.imi. ox.ac.uk/pdfs/the-worlds-potential-migrants

Fischer, P., \& Malmberg, G. (2001). Settled people don't move: On life course and (im-)mobility in Sweden. International Journal of Population Geography, 7(5), 357-371.

Hirschman, A. (1970). Exit, voice, and loyalty: Responses to decline in firms, organizations, and states. Cambridge, MA: Harvard University Press.

Lyon, F. (2000). Trust, networks and norms: The creation of social capital in agricultural economies in Ghana. World Development, 28(4), 663-681. http://dx.doi. org/10.1016/S0305-750X(99)00146-1

Massey, D. S., Arango, J., Hugo, G., Kouaouci, A., Pellegrino, A., \& Taylor, J. E. (1999). Worlds in motion: Understanding international migration at the end of the millennium. Oxford: Clarendon Press.

Quartey, P. (2009). Migration in Ghana: A country profile. Geneva: International Organization for Migration.

Schewel, K. (2015). Understanding the aspiration to stay: A case study of young adults in Senegal (IMI Working Paper No. 107). Oxford: University of Oxford.

Schewel, K. (2019). Understanding immobility: Moving beyond the mobility bias in migration studies. International Migration Review, 54(2). https://doi.org/ 10.1177/0197918319831952

Sen, A. (1997). Editorial: Human capital and human capability. World Development, 25(12), 1959-1961.

Setrana, B. M. (2017). Post-migration outcomes and the decision to return: Processes and consequence on development. African Human Mobility Review, 3(3), 995-1019.

Setrana, B. M., \& Tonah, S. (2016). Do transnational links matter? Labour market participation of Ghanaian return migrants. Journal of Development Studies, 52(4), 549-560. https://doi.org/10.1080/00220388. 2015.1126255

Spijkerboer, T. (2018). The global mobility infrastructure: Reconceptualising the externalisation of migration control. European Journal of Migration and Law, 20, 452-469.

Tonah, S., Setrana, M. B., \& Arthur, J. (Eds.). (2017). Migration and development in Africa: Trends, challenges and policy implications. Lanham, MD: Rowman and Littlefield.

UNDESA. (2020). International migration report 2019. Geneva: United Nations.

\section{About the Author}

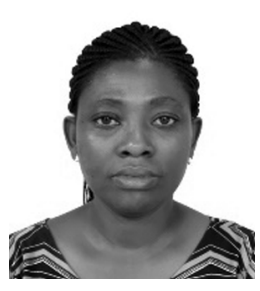

Mary Setrana (PhD) is a Senior Lecturer at the Centre for Migration Studies (CMS), College of Humanities, University of Ghana, Legon, with an affiliation to the Department of Sociology at the University of Johannesburg. She is a Researcher on several national and internationally funded projects including in the Swiss-Sub-Saharan African Migration Network (S-SAM) and the South-South Migration, Inequality and Development (MIDEQ) Hub. Mary has published on a range of migration issues including migration decisions, immobility, citizenship, gender and migration, migration and development in Africa, transnational migration and diasporas and return migration and reintegration, among other topics. 